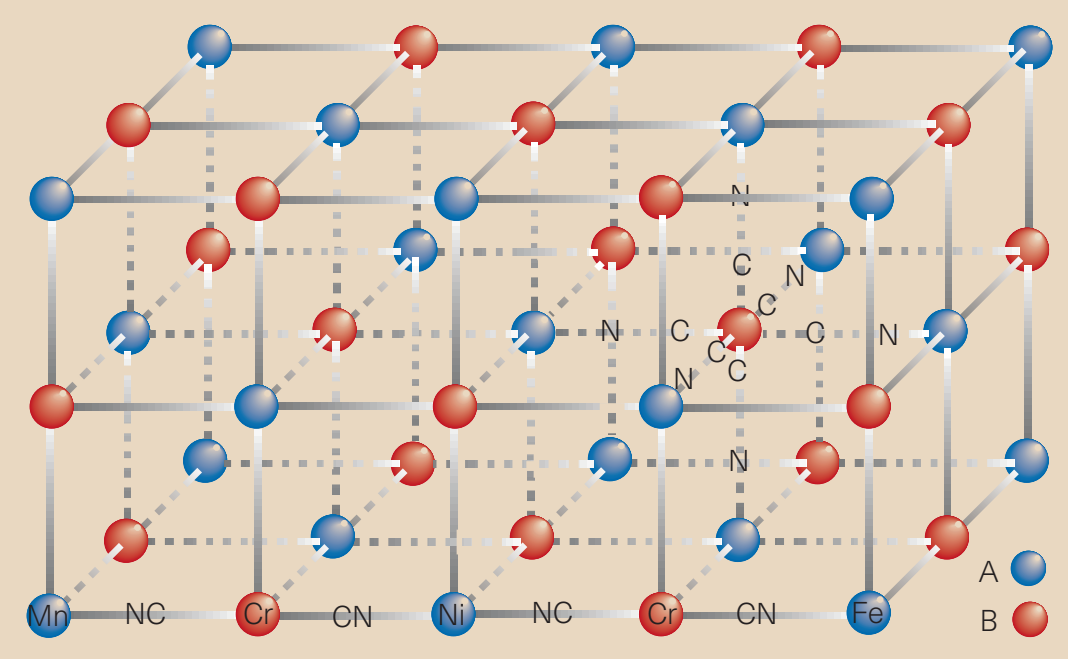

Figure 2 Idealized structure of the Prussian-blue-like phases designed by Hashimoto and colleagues ${ }^{1}$. The phase incorporates four transition metal ions $(\mathrm{Mn}, \mathrm{Cr}, \mathrm{Ni}$ and $\mathrm{Fe}$ ), which produce a mixed ferroferrimagnet capable of switching magnetization twice with changing temperature.

atoms. Moreover, owing to the regularity of the $\mathrm{A}$ and $\mathrm{B}$ sites and of the lattice as a whole, the symmetry rules governing the magnetic properties apply in a straightforward manner ${ }^{5-7}$. So the authors were able to predict whether the compound is ferro- or antiferromagnetic, and to estimate $T_{c}$.

Hashimoto and co-workers focused on compounds of formula $\mathrm{A}_{3}\left[\mathrm{Cr}(\mathrm{CN})_{6}\right]_{2}$. For A $=\mathrm{Ni}$ or $\mathrm{Fe}$, the compound is a ferromagnet, and for $\mathrm{A}=\mathrm{Mn}$ it is a ferrimagnet. First, the authors synthesized compounds incorporating just three transition ions ${ }^{8}$, with the formula $\left(\mathrm{Ni}_{\mathrm{a}} \mathrm{Mn}_{\mathrm{b}}\right)_{3}\left[\mathrm{Cr}(\mathrm{CN})_{6}\right]$, where $\mathrm{a}+\mathrm{b}$ $=1$. With such materials, they succeeded in tuning the temperature dependence of the spontaneous magnetization by changing the chemical composition as defined by a and $b$, but not in obtaining two compensation temperatures. In their latest paper $^{1}$, they worked with compounds incorporating four transition ions, with the formula $\left(\mathrm{Ni}_{\mathrm{a}} \mathrm{Mn}_{\mathrm{b}} \mathrm{Fe}_{\mathrm{c}}\right)_{3}\left[\mathrm{Cr}(\mathrm{CN})_{6}\right]$, where $\mathrm{a}+\mathrm{b}+\mathrm{c}$ $=1$. The spontaneous magnetizations of the $\mathrm{Ni}, \mathrm{Fe}$ and $\mathrm{Cr}$ sub-lattices are all positive, whereas that of the Mn sub-lattice is negative, producing a mixed ferroferrimagnet.

Using their simplified molecular-field theory calculation, the authors determined a hypothetical composition - that is, a, b and c values - for which the resulting spontaneous magnetization shows two compensation temperatures. Adding an additional positive contribution ( $\mathrm{Fe}$ ions) results in a positive spontaneous magnetization at temperatures close to absolute zero, and hence a second compensation temperature. Next, they synthesized the material corresponding to this composition, namely $\left(\mathrm{Ni}_{0.22} \mathrm{Mn}_{0.60} \mathrm{Fe}_{0.18}\right)_{3}\left[\mathrm{Cr}(\mathrm{CN})_{6}\right]$. This material is actually a magnet with $T_{\mathrm{c}}=63 \mathrm{~K}$, exhibiting two magnetization reversals, at 53 and 35 K. No other compound of this kind has been obtained before, yet the synthesis of this

unique magnet is surprisingly straightforward. It consists of mixing together at room temperature two aqueous solutions, one containing a mixture of $\mathrm{Ni}, \mathrm{Mn}$ and Fe salts in the ratio a:b:c, the other containing the $\left[\mathrm{Cr}(\mathrm{CN})_{6}\right]^{3-}$ complex. The expected material then forms as a powder. More generally, Prussian-blue-like phases are prepared from molecular precursors in very mild conditions, which provides a remarkable flexibility in terms of chemical compensation, and consequently of physical behaviours. Hashimoto and colleagues have also created a Prussian-blue-like phase that reversibly Microtechnology

\section{Laying it on thick}

Using an electrochemical fabrication process (called EFAB), Adam Cohen and a team of engineers at the University of Southern California have made several multi-layered structures, such as the 12layer nickel chain shown here that has six freely moving links. The chain is not much thicker than a sheet of paper, probably making it the world's thinnest. But for the engineers who created it, the most exciting thing about the chain is not its size, but the process used to build it.

The EFAB technique can produce arbitrary 3-D micro-devices in a simple, automated process. EFAB is inspired by the commercial process of 'rapid prototyping', which uses a stacking procedure to build a solid object from layers hundreds of micrometres thick. Devices made by rapid prototyping are usually plastic, whereas EFAB can create metal objects from layers that are 5-8 $\mu \mathrm{m}$ or less.

Each layer is made by depositing a 'sacrificial' material using a high-speed 'instant masking' technique, followed by a switches from a paramagnetic to a ferromagnetic state in response to light ${ }^{9}$.

The first two molecule-based magnets were reported in $1986^{10,11}$. Since that pioneering work, quite a few research groups have initiated some activity along this line (see for instance ref. 12), and today several dozens of magnets synthesized from molecular precursors are known. The chemists and physicists who work in this field of research are sometimes asked to specify what are the new features arising from the molecular nature of the materials. The rational design of a magnet with two reversals of the magnetization may now be considered as one of the answers.

Olivier Kahn is in the Laboratoire des Sciences

Moléculaires, Institut de Chimie de la Matière

Condensée de Bordeaux (ICMCB), 33608 Pessac,

France.

e-mail: olivier.kahn@icmcb.u-bordeaux.fr

1. Ohkoshi, S., Abe, Y., Fujishima, A. \& Hashimoto, K. Phys. Rev. Lett. 62, 1285-1288 (1999).

2. Néel, L. Ann. Phys. (Leipz.) 3, 137 (1948).

3. Blasse, G. \& Gorter, E. W. J. Phys. Soc. (Jpn. Suppl. B-1) 17, 176-182 (1962)

4. Mathonière, C., Nuttal, C. J., Carling, S. G. \& Day, P. Inorg. Chem. 35, 1201-1206 (1996).

5. Kahn, O. Molecular Magnetism (VCH, New York, 1993).

6. Mallah, T., Thiébault, S., Verdaguer, M. \& Veillet, P. Science 262, 1554-1557 (1993).

. Kahn, O. Nature 378, 667-668 (1995).

8. Ohkoshi, S., Iyoda, T., Fujishima, A. \& Hashimoto, K. Phys. Rev. B 56, 11642-11652 (1997).

9. Sato, O. et al. Science 272, 704-705 (1996).

10. Miller, J. S. et al. J. Chem. Soc. Chem. Commun. 1026-1028 (1986).

11. Pei, Y., Verdaguer, M., Kahn, O., Sletten, J. \& Renaud, J. P. J. Am. Chem. Soc. 108, 428-429 (1986)

12. Proc. 5th Int. Conf. Molecule-Based Magnets (eds Itoh, K., Millar, J. S. \& Takui, T.) Mol. Cryst. Liq. Cryst. 305, 306 (1996).

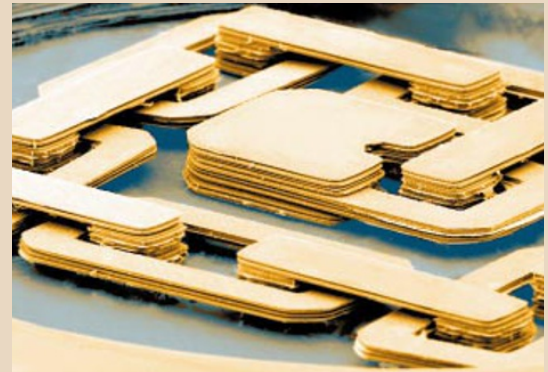

blanket deposit of metal. The layer is levelled, and the process repeats, following a computer-generated pattern. Chemically etching away the sacrificial material leaves behind the desired 3-D structure. Instant masking uses a prefabricated plate that deposits material much like a printing press, making the whole process quicker.

Traditional micro-fabrication requires customized processes, and expensive cleanrooms. Through mass production, EFAB promises to substantially lower the costs of producing many micro-scale devices.

Sarah Tomlin 